\title{
CELLULOSE BASED LUMINOPHORE MATERIAL
}

\author{
IRENA KOSTOVA, ${ }^{*}$ TINKO EFTIMOV, ${ }^{* * * * * *}$ STEFKA NACHKOVA, \\ GEORGI PATRONOV* and ALLA ARAPOVA** \\ *Department of Chemical Technology, \\ University of Plovdiv "Paisii Hilendarski", Plovdiv, Bulgaria \\ ** Department of Informatics and Engineering, University of Quebec in Outaouais, Gatineau, Canada \\ "Central Laboratory of Applied Physics, Bulgarian Academy of Sciences, Plovdiv, Bulgaria \\ \Corresponding author: I. Kostova, irena_k87@abv.bg
}

Received October 30, 2019

In the present work, the synthesis of strontium aluminates has been performed aiming at obtaining different emission colours induced by excitation with various sources from the near UV and visible spectrum domain and identifying the most appropriate of them. Also, the study included the incorporation of the resulting phosphors into polymers in the form of thin films, as well as the preparation of polymer/cellulose/luminophore composites. According to the above, the main purpose of the present work has been to obtain hybrid composite materials. The study involved the investigation of their structure and properties. According to the reported results, the developed micro-sized luminescent strontium aluminates have strong potential to be used as fillers in paper, polymers or hybrid materials. The use of the phosphorescent particle filler in polymer/cellulose materials can increase the security features of the materials to the second level.

Keywords: strontium aluminates, composites, fluorescence, cellulose

\section{INTRODUCTION}

The importance of luminescent nano- or micro-materials is due to the possibility to model specific properties, which may be recognizable employing special devices. Luminescent materials have found a wide range of applications in everyday life, including optical displays, lighting, scintillators and many more. These materials are typically characterized by light emitted in the visible range, but there are also those emitting in other spectral regions (ultraviolet and infrared). ${ }^{1-3}$ The growing demand for new luminescent materials focuses on the efforts to improve the characteristics of existing and promote the development of new and effective luminescent nanomaterials, with the desired shape, size and morphology, optical properties and others. They have a wide range of applications, such as photovoltaic, biomedical, security technology, solar lighting, displays etc. ${ }^{4}$ One of their most important applications is in the development of security inks. These nano- or micro-materials can easily and inexpensively be applied to different surfaces and are widely used as protective inks for documents, pharmaceuticals and higher-value goods. Counterfeiting is a global problem, as well as a challenge for companies, governments and customers. ${ }^{5,6}$ Luminescent markers are the most popular security components in authentic document protection. Typical examples are banknotes that show luminescent areas under UV light. $^{7}$

It is known that strontium aluminates are strong phosphors, some of them with a significant afterglow duration. The majority of the studied strontium aluminates are doped with europium and dysprosium to obtain a higher luminescent effect. They can also be doped with other rare earth metals, which can lead to different luminescent colours. Also, the stoichiometry, the methods of preparation and the reductive atmosphere can affect the luminescent properties of strontium aluminate phosphors. This material is non-toxic, chemically durable and can be subjected to mechanical treatment for reducing its particle size. ${ }^{6,7}$ These properties of strontium aluminates make them suitable for use as additives in different matrices.

Incorporating the luminescent particles into a polymer structure is a typical way to produce security components resistant to mechanical and environmental impacts in long-term usage. For document protection, flexibility and strength are 
desirable properties, achievable by combining cellulose with appropriate synthetic polymers. In papermaking, polymers are used as binding agent between cellulose fibers and some pigments or fillers, for surface modification and printing compatibility improvement, etc. ${ }^{8}$ Conversely, in polymer-based materials, cellulose fibres are added mainly for reinforcement and biodegradability enhancement, being advantageous by their non-toxic nature, low density and low cost, wide availability and renewability of resources. ${ }^{9,10}$ These mutual benefits allow for designing composites that can be functionalized for specific purposes.

We present the preparation of a threecomponent hybrid material, containing micro-size luminophores (strontium aluminates), polymers and cellulose. The work includes the synthesis of luminescent strontium aluminates, the study of their structure and properties by XRD, IR and photoluminescent analyses. This study demonstrates the potential for the application of strontium aluminates with different fluorescent and phosphorescent colours as security fillers in cellulose materials.

\section{EXPERIMENTAL}

\section{Synthesis of luminophores}

The formulations and the visible properties of the prepared samples, tested with a UV lamp after cooling to room temperature, are presented in Table 1.

We used two different methods for the preparation of luminophore materials. As known, strontium aluminates can be synthesized by chemical combustion, ${ }^{11,12}$ sol-gel ${ }^{13}$ and high-temperature solid state reactions, and each of these methods has its advantages and disadvantages. ${ }^{14}$ In this work, the synthesis of strontium aluminates was carried out by combustion (using urea) and high-temperature solid state reaction using boric acid as flux. Sample 1, sample 2 and sample 3 were synthesized by combustion and high-temperature solid state reaction, while sample 4 and sample 5 were synthesized by solid state reaction at $1210{ }^{\circ} \mathrm{C}$.

The methodology of preparation was the following: a stoichiometric quantity of reagents with $10 \mathrm{~mL}$ of distilled $\mathrm{H}_{2} \mathrm{O}$ and urea (carbamide) were mixed; then the aqueous blend was placed into a furnace at temperatures ranging between $500-700{ }^{\circ} \mathrm{C}$, where the combustion reaction occurs. After that, the samples were milled and calcined at $1210{ }^{\circ} \mathrm{C}$ for 4 hours in weak reduction atmosphere produced from active carbon in the furnace. ${ }^{15,16}$

The samples synthesized by the solid state method were characterized qualitatively in terms of colour under an ultraviolet lamp and visible light. Three visible fluorescence colours have been achieved green, orange and red. This is due to the distinctive character of lanthanide ion emissions and the crystal matrix.

The resulting samples were in the form of powder, or a hard but crumbly mass that allowed grinding. Grinding was achieved with a laboratory vibratory ball mill up to micro-size. The reduction in particle size did not significantly affect the emission intensity, which is satisfactory, given that such a disadvantageous effect is theoretically possible. Fine grinding of powder allows it to attach to paper pores, and this feature can be used to temporarily mark banknotes and other documents.

\section{Preparation of luminescent polymer}

The synthesized luminescent materials were tested for their compatibility with various polymers, as well as for combining them with cellulose in a tricomponent composite. Several types of polymers were used: polyethylene oxide (PEO), polyvinyl pyrrolidone (PVP), polymethyl methacrylate (PMMA) and polyvinyl alcohol (PVA). At first, a solution of each particular polymer was prepared by dissolving $0.5 \mathrm{~g}$ granules into $10 \mathrm{~mL}$ of an appropriate solvent (water for PEO, PVP and PVA; chloroform for PMMA). The composites were prepared by mixing $0.2 \mathrm{~g}$ solid particles of luminophore with the liquid polymer phase (solved polymer), homogenizing by ultrasound (to prevent air bubbles) and pouring the suspension onto a solid substrate.

Table 1

Contents and visible properties of the samples

\begin{tabular}{|c|c|c|c|c|}
\hline Sample & Starting reagents & $\begin{array}{l}\text { Stoichiometric } \\
\text { formula }\end{array}$ & $\begin{array}{l}\text { Visible color of emission } \\
\text { under UV lamp }\left(\lambda_{\mathrm{ex}}=405 \mathrm{~nm}\right)\end{array}$ & Afterglow \\
\hline 1 & $\begin{array}{c}\mathrm{SrCO}_{3} ; \mathrm{Al}_{2} \mathrm{O}_{3} ; \mathrm{nCO}\left(\mathrm{NH}_{2}\right) \\
\mathrm{H}_{3} \mathrm{BO}_{3}\end{array}$ & $\mathrm{Sr}_{4} \mathrm{Al}_{14} \mathrm{O}_{25}: \mathrm{Mn}_{0.01}$ & the & no \\
\hline 2 & $\begin{array}{c}\mathrm{SrCO}_{3} ; \mathrm{Al}\left(\mathrm{NO}_{3}\right)_{3} ; \mathrm{CO}\left(\mathrm{NH}_{2}\right) ; \\
\mathrm{H}_{3} \mathrm{BO}_{3}\end{array}$ & $\mathrm{Sr}_{3} \mathrm{Al}_{2} \mathrm{O}_{6}: \mathrm{Eu}_{1.0}$ & orange and green & yes \\
\hline 3 & $\begin{array}{c}\mathrm{SrCO}_{3} ; \mathrm{Al}\left(\mathrm{NO}_{3}\right)_{3} \\
\mathrm{~B}_{2} \mathrm{O}_{3}\end{array}$ & $\mathrm{SrAl}_{2} \mathrm{O}_{4}: \mathrm{Eu}_{1.0} \mathrm{Dy}_{1.0}$ & green & yes \\
\hline 4 & $\mathrm{SrCO}_{3} ; \mathrm{Al}\left(\mathrm{NO}_{3}\right)_{3}$ & $\mathrm{Sr}_{3} \mathrm{Al}_{2} \mathrm{O}_{6}: \mathrm{Eu}_{1.0} \mathrm{Dy}_{2.0}$ & green & yes \\
\hline 5 & $\begin{array}{c}\mathrm{SrCO}_{3}(10 \% \text { more }) ; \mathrm{Al}_{2} \mathrm{O}_{3} ; \\
\mathrm{H}_{3} \mathrm{BO}_{3}\end{array}$ & $\mathrm{SrAl}_{2} \mathrm{O}_{4}: \mathrm{Eu}_{1.0} \mathrm{Dy}_{2.0}$ & green & yes \\
\hline
\end{tabular}




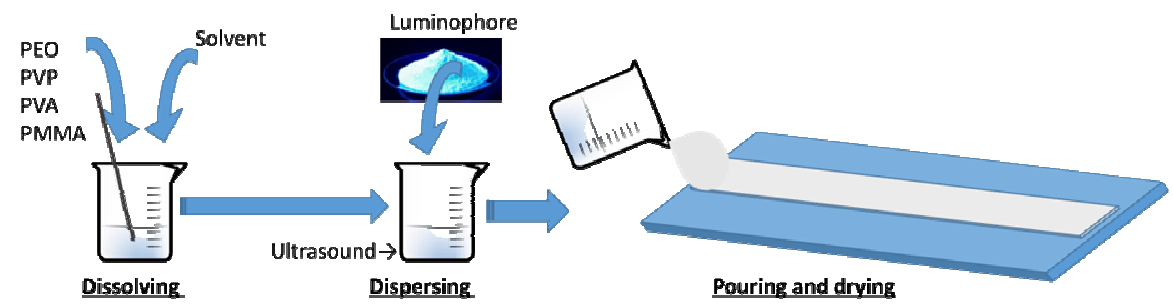

Scheme 1: Preparation of luminescent polymer

After drying, thin luminescent films were obtained. The preparation procedure is presented in Scheme 1. For the polymer-cellulose-luminophore type composite, $2 \mathrm{~g}$ of cellulose well dispersed in $100 \mathrm{~mL}$ of water was added to the other two components after their homogenization and mixed thoroughly.

\section{Materials}

The following analytical grade reagents were used for the preparation of strontium aluminates: $\mathrm{SrCO}_{3}$, $\mathrm{Al}_{2} \mathrm{O}_{3}, \mathrm{H}_{3} \mathrm{BO}_{3}, \mathrm{CO}\left(\mathrm{NH}_{2}\right), \mathrm{Eu}_{2} \mathrm{O}_{3}, \mathrm{Dy}_{2} \mathrm{O}_{3}, \mathrm{MnO}_{2}-$ all of them were purchased from Alfa Aesar. To produce a weak reduction atmosphere for high-temperature synthesis, we used activated carbon (granulated) also purchased from Alfa Aesar.

For the preparation of polymeric solutions, we used granulated polymers: polyethylene oxide (PEO), polyvinylpyrrolidone (PVP), polyvinyl alcohol (PVA) and polymethyl methacrylate (PMMA), and their appropriate solvents: distilled water and chloroform.

The composite material was prepared with synthesized luminophores, PEO and white cellulose.

\section{Methods of analysis}

Infrared spectra were recorded on a Vertex 70 FTIR spectrometer (Bruker Optics), in the spectral region between 4000-400 $\mathrm{cm}^{-1}$, with a resolution of $2 \mathrm{~cm}^{-1}$.

The photoluminescence analysis was performed using a monochromator (MonoScan 2000, Ocean Optics) at an excitation wavelength $\lambda_{\text {exc }}$ from $220 \mathrm{~nm}$ to $850 \mathrm{~nm}$, and the spectral distribution was observed by a spectrometer (Ocean Optics, QE65000).

$\mathrm{X}$-ray powder diffraction data were collected on a Bruker diffractometer, operating with a $\mathrm{Cu}-\mathrm{K} \alpha$ radiation source $(\lambda=1.5406 \mathrm{~nm})$, in steps of 0.020 over the $2 \theta$ range of $10-800$, with a time per step of 2.8 seconds. The crystalline phases were identified using the powder diffraction files PDF 00-005-0418, 00-0241187, 00-028-1222, 00-034-0379, 00-034-0392, 00052-1876, 00-054-0231，01-070-9237，01-072-2245, 01-075-9212 and 01-076-7488 from ISDD PDF-2 database using DiffractPlus EVA v.12 program (2009) [DiffractPlus EVA v.12 program and ICDD (The International Centre for Diffraction Data) PDF-2 database (2009)].
Thermal analysis was performed on a TA Instruments DSC Q100, in the temperature range of 0$590{ }^{\circ} \mathrm{C}$, with a ramp of $5{ }^{\circ} \mathrm{C} / \mathrm{min}$.

The density of the composite material was calculated by Equation (1):

$$
\rho=\frac{m}{V}=\frac{m}{W \cdot L \cdot T}
$$

where $m(\mathrm{~g})$ is the mass of the sample, $W(\mathrm{~cm})$ is the width, $L(\mathrm{~cm})$ is the length, and $T(\mathrm{~cm})$ is the thickness. $^{17}$

\section{RESULTS AND DISCUSSION XRD analysis}

Figures 1,2 and 3 show the results of the $X$ ray analysis of three samples with the strongest radiation intensities, namely samples 3,4 and 5 . As can be seen from the X-ray diffraction patterns, several mixed crystalline phases are determined in the composition of samples 3 and 4, whereas the X-ray of sample 5 shows the formation of only one crystal phase - the target of the synthesis.

Figures 1 and 2 show the formation of several crystalline phases, which have been identified by the crystallographic data given in Table 2 and Table 3, respectively. The crystalline phases formed in sample 3 consisted in different complex aluminate oxides: $\mathrm{Sr}_{4} \mathrm{Al}_{14} \mathrm{O}_{25}$ (orthorhombic), $\mathrm{SrAl}_{2} \mathrm{O}_{4}$ (monoclinic), EuSrAlO $\mathrm{Al}_{4}$ (tetragonal) and non-reacted $\mathrm{Eu}_{2} \mathrm{O}_{3}$ (cubic).

In sample 4 , we found a mixture of aluminate carbonate, aluminate oxides and hydroxides. The diffraction peaks can be indexed as orthorhombic $\mathrm{SrCO}_{3}$, tetragonal $\mathrm{Sr}_{2.25} \mathrm{Sm}_{0.75} \mathrm{AlO}_{4.875}$, orthorhombic $\mathrm{Sr}(\mathrm{OH})_{2} \cdot \mathrm{H}_{2} \mathrm{O}$, monoclinic $\mathrm{Sr}_{10} \mathrm{Al}_{6} \mathrm{O}_{19}$, cubic $\mathrm{Sr}_{3} \mathrm{Al}_{2} \mathrm{O}_{6}$ and cubic $\mathrm{Sr}_{3} \mathrm{Al}_{2}(\mathrm{OH})_{12}$. Depending on the stoichiometric ratio, the temperature and the synthesis method, it is possible to produce different single or mixed strontium aluminate crystalline phases. ${ }^{18}$ 


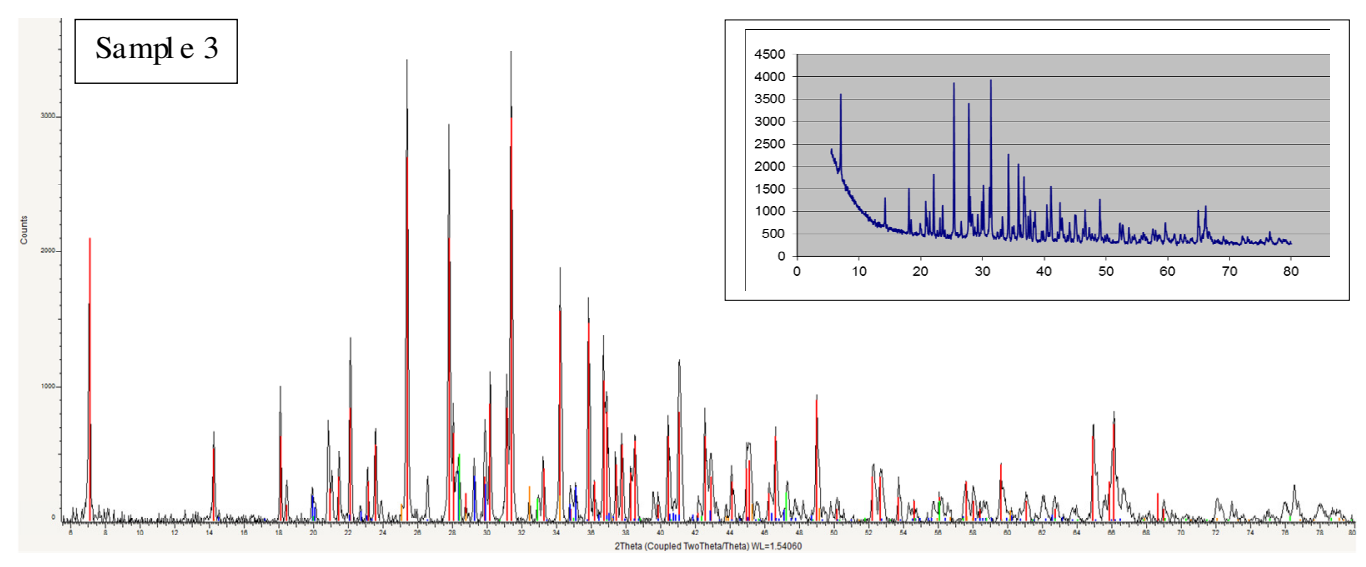

Figure 1: X-ray diffraction pattern of sample 3

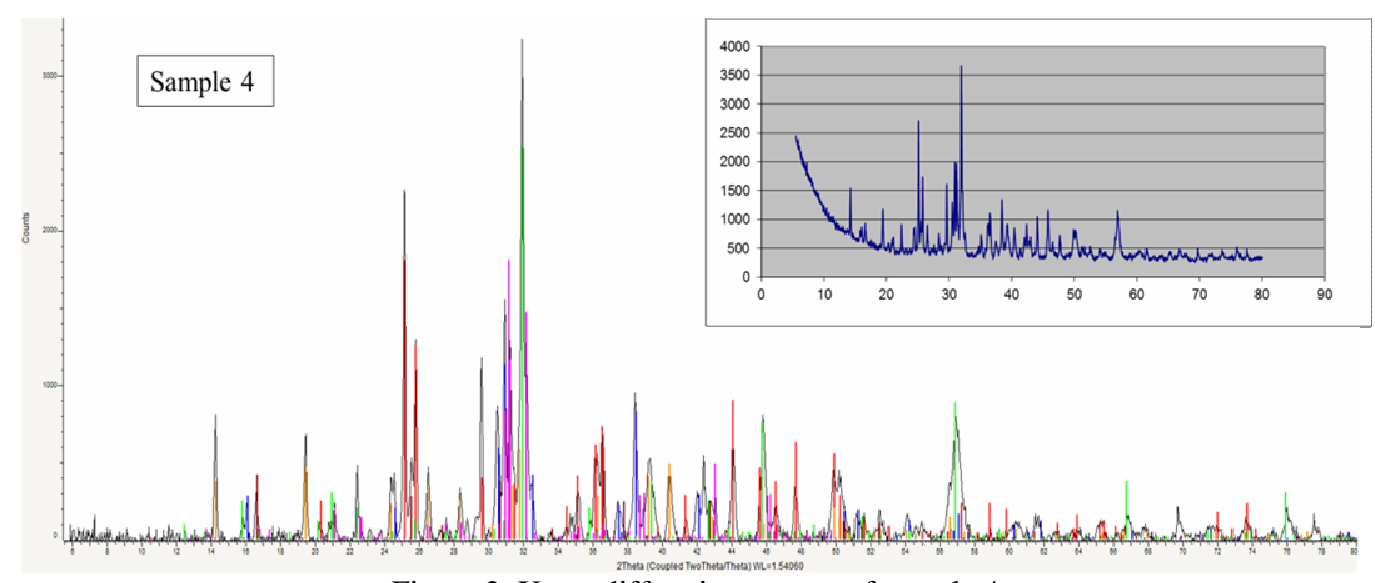

Figure 2: X-ray diffraction pattern of sample 4

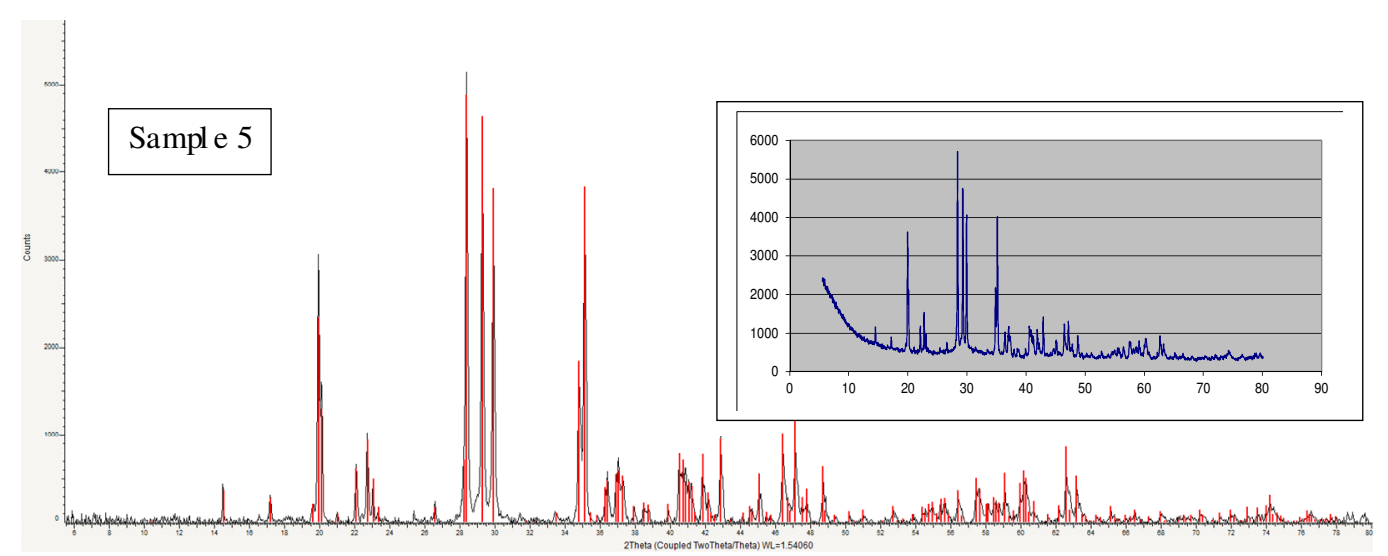

Figure 3: X-ray diffraction pattern of sample 5 
Table 2

Crystallographic data of sample 3

\begin{tabular}{|c|c|c|c|c|c|c|c|c|}
\hline Chemical formula / name & 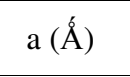 & 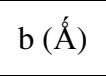 & c $(\AA \grave{)})$ & $\begin{array}{l}\text { Space } \\
\text { group }\end{array}$ & $\begin{array}{c}\rho \\
\left(\mathrm{g} / \mathrm{cm}^{3}\right)\end{array}$ & V $(\AA ̊)$ & $\begin{array}{c}\text { Molecular } \\
\text { weight }\end{array}$ & Ref. \\
\hline $\mathrm{Sr}_{4} \mathrm{Al}_{14} \mathrm{O}_{25} /$ & 8.4859 & 24.791 & 4.8863 & Pmma (51) & 3.645 & 1027.95 & \multirow{2}{*}{1128.21} & PDF 00-052-1876 \\
\hline Strontium aluminum oxide & 8.486 & 24.791 & 4.886 & Pmmb (51) & 3.636 & 1027.95 & & (ICDD, 2019) \\
\hline $\mathrm{SrAl}_{2} \mathrm{O}_{4} /$ & 8.4424 & 8.822 & 5.1607 & $\mathrm{P} * / *$ & \multirow{2}{*}{3.559} & 383.68 & \multirow{2}{*}{205.58} & PDF 00-034-0379 \\
\hline Strontium aluminum oxide & 8.442 & 8.822 & 5.161 & $\mathrm{P} * / *$ & & 383.68 & & (ICDD, 2019) \\
\hline $\mathrm{Eu}_{2} \mathrm{O}_{3} /$ & 10.8683 & \multirow{2}{*}{10.868} & \multirow{2}{*}{10.868} & Ia-3 (206) & \multirow{2}{*}{7.283} & 1283.76 & \multirow{2}{*}{351.92} & PDF 00-034-0392 \\
\hline Europium oxide & 10.868 & & & Ia-3 (206) & & 641.88 & & (ICDD, 2019) \\
\hline $\mathrm{EuSrAlO}_{4} /$ & 3.703 & \multirow{2}{*}{3.703} & 12.39 & I4/mmm (139) & \multirow{2}{*}{6.46} & 169.89 & \multirow{2}{*}{330.56} & PDF 01-075-9212 \\
\hline Strontium europium aluminum oxide & 3.703 & & 12.39 & I4/mmm (139) & & 84.95 & & (ICDD, 2019) \\
\hline
\end{tabular}

Table 3

Crystallographic data of sample 4

\begin{tabular}{|c|c|c|c|c|c|c|c|c|}
\hline Chemical formula / name & $\mathrm{a}(\AA \hat{)})$ & $\mathrm{b}(\AA)$ & $c(\AA \hat{)})$ & $\begin{array}{l}\text { Space } \\
\text { group }\end{array}$ & $\rho\left(\mathrm{g} / \mathrm{cm}^{3}\right)$ & $\mathrm{V}\left(\AA^{3}\right)$ & $\begin{array}{c}\text { Molecular } \\
\text { weight }\end{array}$ & Ref. \\
\hline $\mathrm{SrCO}_{3} /$ & 5.107 & 8.414 & 6.029 & Pmcn (62) & 3.785 & 259.07 & & PDF 00-005-0418 \\
\hline Strontium carbonate & 5.107 & 8.414 & 6.029 & Pmcn (62) & 3.76 & 259.07 & $14 / .03$ & (ICDD, 2019) \\
\hline $\mathrm{Sr}_{2.25} \mathrm{Sm}_{0.75} \mathrm{AlO}_{4.875} /$ & 6.7766 & 6.7766 & 10.9918 & $\mathrm{I} 4 / \mathrm{mcm}(140)$ & \multirow[b]{2}{*}{5.46} & 504.77 & \multirow{2}{*}{414.92} & PDF 00-054-0231 \\
\hline Strontium aluminum samarium oxide & 6.777 & 6.777 & 10.992 & $\mathrm{I} 4 / \mathrm{mcm}(140)$ & & 504.77 & & (ICDD, 2019) \\
\hline $\mathrm{Sr}(\mathrm{OH})_{2} \cdot \mathrm{H}_{2} \mathrm{O} /$ & 6.201 & 6.716 & 3.6483 & $\mathrm{~Pb} 21 \mathrm{~m}(26)$ & \multirow{2}{*}{3.052} & 151.94 & \multirow{2}{*}{139.65} & PDF 00-028-1222 \\
\hline Strontium hydroxide hydrate & 6.201 & 6.716 & 3.648 & $\mathrm{~Pb} 21 \mathrm{~m}(26)$ & & 151.94 & & (ICDD, 2019) \\
\hline $\mathrm{Sr}_{10} \mathrm{Al}_{6} \mathrm{O}_{19} /$ & 34.5823 & 7.8460 & 15.7485 & $\mathrm{C} 2 / \mathrm{c}(15)$ & \multirow{2}{*}{4.294} & 14151.86 & \multirow{2}{*}{1342.08} & PDF 01-070-9237 \\
\hline Decastrontium hexaaluminum oxide & 34.443 & 7.846 & 15.748 & $\mathrm{I} 2 / \mathrm{a}(15)$ & & 2075.93 & & (ICDD, 2019) \\
\hline $\mathrm{Sr}_{3} \mathrm{Al}_{2} \mathrm{O}_{6} /$ & 15.844 & 15.844 & 15.844 & $\mathrm{~Pa}-3(205)$ & \multirow{2}{*}{4.136} & 3977.36 & \multirow{2}{*}{412.82} & PDF 00-024-1187 \\
\hline Strontium aluminum oxide & 15.844 & 15.844 & 15.844 & $\mathrm{~Pa}-3(205)$ & & 3977.36 & & (ICDD, 2019) \\
\hline $\mathrm{Sr}_{3} \mathrm{Al}_{2}(\mathrm{OH})_{12} /$ & 13.031 & 13.031 & 13.031 & Ia-3d (230) & 3.127 & 2212.75 & \multirow{2}{*}{520.91} & PDF 01-072-2245 \\
\hline Strontium aluminum hydroxide & 13.031 & 13.031 & 13.031 & Ia-3d (230) & 3.13 & 1106.38 & & (ICDD, 2019) \\
\hline
\end{tabular}




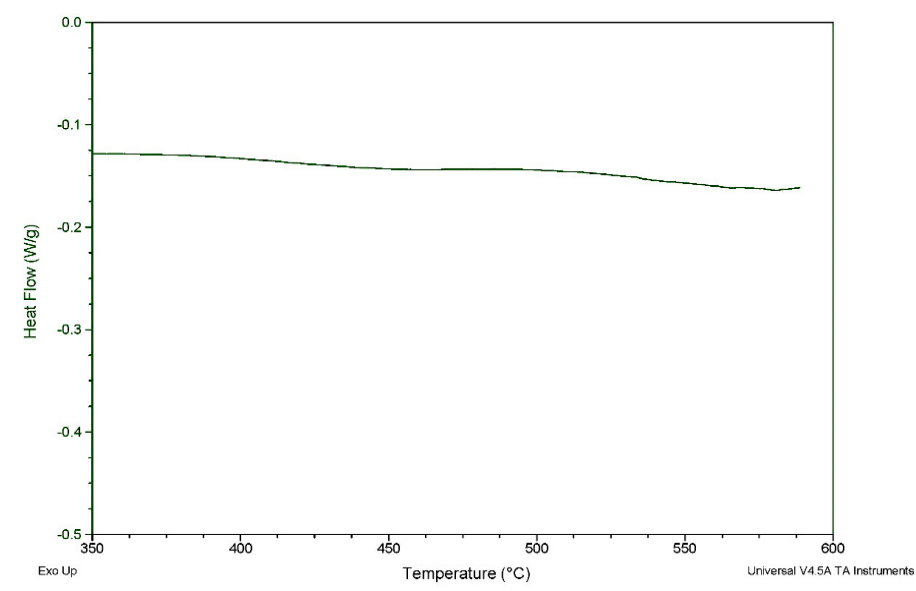

Figure 4: Thermogram of sample 5

From the X-ray graph given in Figure 3, only one crystalline phase, registered as strontium aluminium oxide (strontium dialuminate), with the chemical formula $\operatorname{Sr}\left(\mathrm{Al}_{2} \mathrm{O}_{4}\right)$, was identified with the following lattice parameters: $a: 8.44365$ $\AA$, $b$ : $8.82245 \AA$, volume: $383.68 \AA^{3}$, space group: P21 (4) - monoclinic, density: $3.559 \mathrm{~g} / \mathrm{cm}^{3}$, molecular weight: 205.58 [PDF 01-076-7488 (ICDD, 2019)]. The formation of the single phase was confirmed by DSC analysis, because it did not record phase transitions (glass transition, crystallization or melting) up to $600{ }^{\circ} \mathrm{C}$ (given in Fig. 4). This means that the sample was hightemperature resistant and in non-amorphous state.

\section{Photoluminescent analysis of strontium aluminates}

The photoluminescent analysis was performed by illuminating the sample by a monochromator (MonoScan 2000, Ocean Optics), at an excitation wavelength $\lambda_{\text {exc }}$ from $220 \mathrm{~nm}$ to $850 \mathrm{~nm}$, and the spectral distribution of the luminescence (fluorescence or phosphorescence) was observed by a spectrometer (Ocean Optics, QE65000). This distribution usually exhibits a maximum at a wavelength $\lambda_{\mathrm{em}}$. The difference is a spectral offset related to the Stokes shift (Eq. 2):

$\Delta \lambda=\lambda_{\mathrm{em}}-\lambda_{\mathrm{exc}}$

The results are presented in the form of $3 \mathrm{D}$ excitation-emission graphs and 2D topographic projections, which permit the accurate determination of the most efficient excitation wavelength and the determination of the spectral off-set.
Sample $1\left(\mathrm{Sr}_{4} \mathrm{Al}_{14} \mathrm{O}_{26}: \mathrm{Mn}\right)$, the manganeseactivated sample, emits in the orange-red range of the spectrum at a maximum of $658 \mathrm{~nm}$. As can be seen from the results in Figure $5(a, b)$, the most effective source of excitation is the wavelength of $350 \mathrm{~nm}$. Hence, the spectral offset is $\Delta \lambda=658 \mathrm{~nm}$ $-350 \mathrm{~nm}=308 \mathrm{~nm}$, which is almost twice larger than that for $\mathrm{SrAl}_{2} \mathrm{O}_{4}$ : EuDy (sample 5).

The 3D graph in Figure 6 (a) shows two strong emission peaks of the europium-activated sample, produced by excitation sources at 360 and 480 $\mathrm{nm}$, which can also be seen in the 2D graph (Fig. $6 \mathrm{~b})$. The intensity maxima are at $520 \mathrm{~nm}$ (green) and $620 \mathrm{~nm}$ (orange-red), which correspond to the ionization of europium as $\mathrm{Eu}^{2+}$ and $\mathrm{Eu}^{3+}$, respectively. The spectral offsets are found to be different and are correspondingly $\Delta \lambda_{1}=520 \mathrm{~nm}-$ $360 \mathrm{~nm}=160 \mathrm{~nm}$, and $\Delta \lambda_{2}=620 \mathrm{~nm}-480 \mathrm{~nm}=$ $140 \mathrm{~nm}$.

Photoluminescent spectra at excitation wavelengths in the $300-400 \mathrm{~nm}$ range were obtained for sample $5-\mathrm{SrAl}_{2} \mathrm{O}_{4}$ : EuDy (Fig. 7). The spectra indicate an increase in the intensity of the sample emission by increasing the excitation wavelength until $360-380 \mathrm{~nm}$. The results show peaks in the visible area of the spectrum: a few low intensity peaks around $700 \mathrm{~nm}$ (dark red) and a high intensity wide peak with a maximum at $520 \mathrm{~nm}$ (green). Looking at the topographic 2D representation (Fig. 7 b) the most efficient sources are at $360 \mathrm{~nm}$ for the green emission, and at 300320 for the orange-red emission. The spectral offset is then $\Delta \lambda=520 \mathrm{~nm}-360 \mathrm{~nm}=160 \mathrm{~nm}$. 

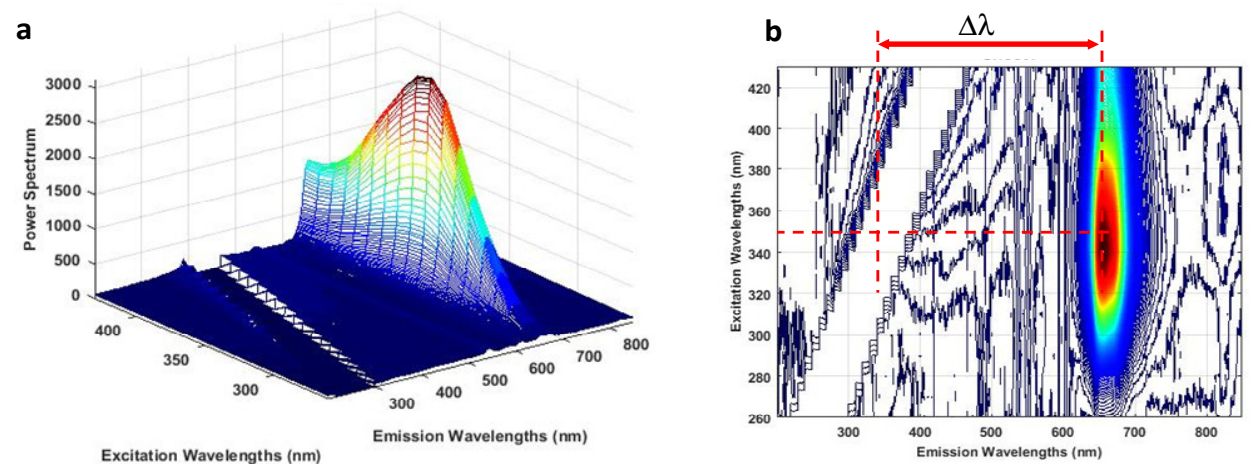

Figure 5: Photoluminescent excitation emission spectra of sample $\mathrm{Sr}_{4} \mathrm{Al}_{14} \mathrm{O}_{25}$ :Mn (sample 1)
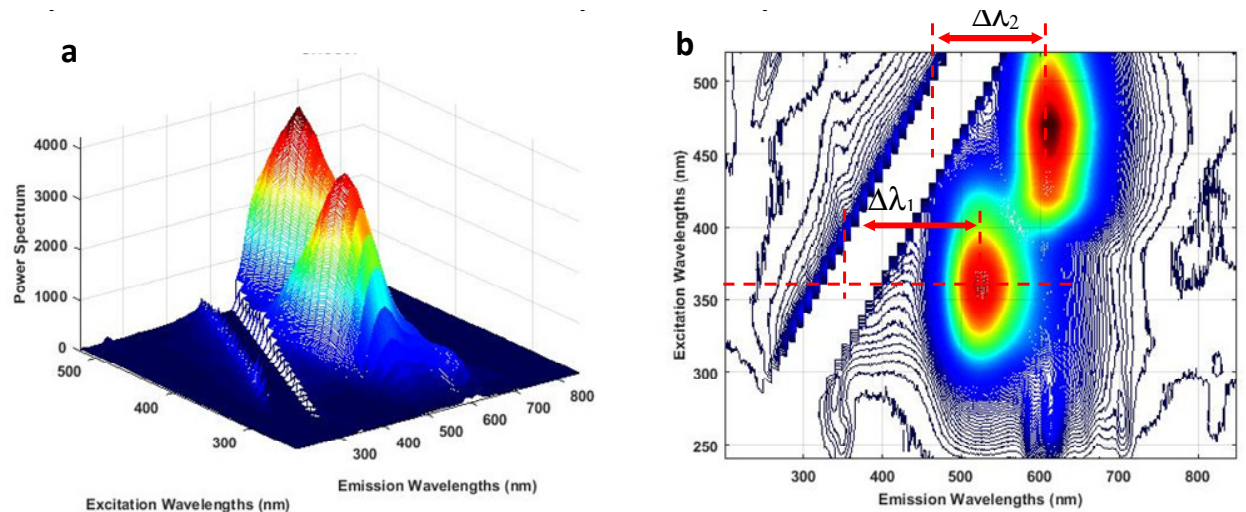

Figure 6: 3D (a) and 2D (b) excitation emission graphs of $\mathrm{Sr}_{3} \mathrm{Al}_{2} \mathrm{O}_{6}$ : $\mathrm{Eu}$ (sample 2)
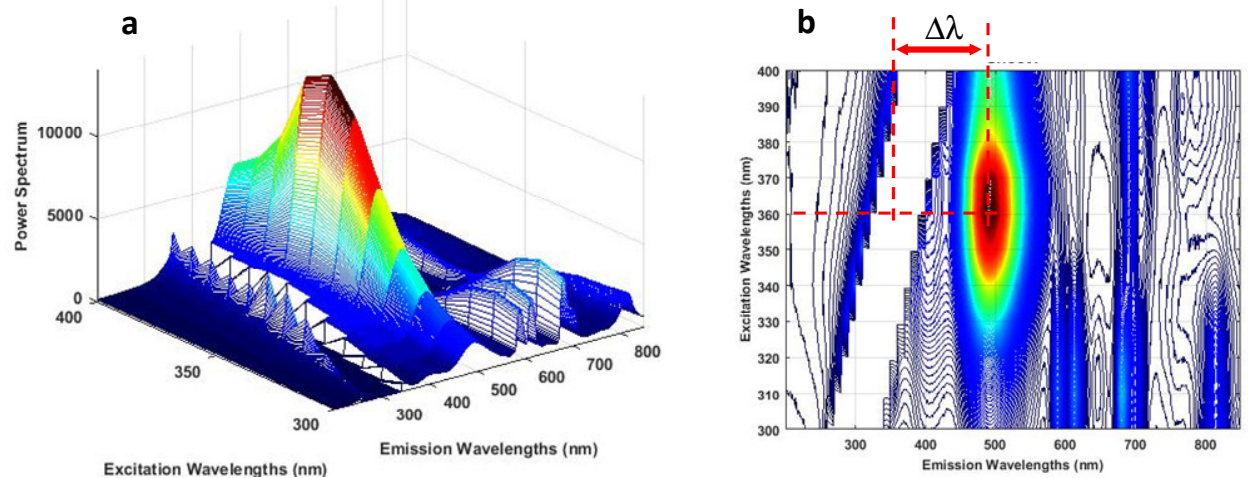

Figure 7: Photoluminescent spectrum of sample $\mathrm{SrAl}_{2} \mathrm{O}_{4}$ :Eu,Dy (sample 5)

\section{Infrared spectroscopy}

Sample 5 was the only sample with a single phase formation and its IR spectrum can be interpreted clearly, unlike the spectra of the other samples.

In the infrared spectrum of sample 5 (Fig. 8), the absorption band characteristics of the O-Al-O bond vibrations in the crystalline structure of $\mathrm{SrAl}_{2} \mathrm{O}_{4}$ have been identified: $\delta_{\mathrm{s}} 420,447 \mathrm{~cm}^{-1}$ (symmetric deformation); $\delta_{\text {as }} 556,593,622,647$ $\mathrm{cm}^{-1}$ (antisymmetric deformation); $\gamma_{\mathrm{s}} 784,804$, $848,895 \mathrm{~cm}^{-1}$ (antisymmetric stretching) and $\gamma_{\mathrm{as}}$ $711 \mathrm{~cm}^{-1}$ (symmetric stretching). The bands in the $588-845 \mathrm{~cm}^{-1}$ range can also be referred to as the Sr-O bond oscillation. ${ }^{19}$ The bands at 784, 895 $\mathrm{cm}^{-1}$ and the most intense band at $848 \mathrm{~cm}^{-1}$ are an indication of the presence of tetrahedral aluminium coordination $\left[\mathrm{AlO}_{4}\right]$ in the crystalline structure of $\mathrm{SrAl}_{2} \mathrm{O}_{4}$. The widened bands at about $1200-1300 \mathrm{~cm}^{-1}$ are probably due to a stretching 
vibration of the $\mathrm{B}-\mathrm{O}$ bond in the $\mathrm{BO}_{3}$ amorphous phase. ${ }^{11}$ The infrared spectrum of sample 5 corresponds to the results of X-ray analysis.

\section{Analysis of produced composite materials}

The produced composite materials consist of inorganic luminescent particles dispersed in a polymer matrix with or without cellulose fibres. The best compatibility was established using PEO, the resulting films being homogeneous, easy to separate from the substrate, and significantly better in strength than the others, which were brittle after drying (Fig. 9).

The luminous properties of the powders are preserved after mixing with each of the tested polymers. On the other hand, polyethylene oxide is compatible with other polymers, which allows for desirable properties depending on the application. It is also non-toxic and, unlike other polymers, is highly thermoplastic.
The polymer-cellulose-luminophore type was prepared by mixing the three components, pouring the slurry and drying. For this purpose, PEO polymer solution, bleached cellulose and various luminescent samples were used. The result is given in the photographs in Figure 10.

The resulting composite has good density and thickness. The density of a piece from the composite material, with the dimensions ( $\mathrm{W} \times \mathrm{L}$ ) of $5.1 \mathrm{~cm} \times 2.4 \mathrm{~cm}$, thickness (T) of $0.02 \mathrm{~cm}$, and mass of $0.1209 \mathrm{~g}$, was calculated according to Equation (1). The result was $\rho=0.4939 \mathrm{~g} / \mathrm{cm}^{3}$. As can be seen from the photos, the luminescent particles are sealed in the cellulose and the polymer, thus reducing the likelihood of being separated. Also, without being activated by UV light, they are not noticeable in the paper volume. A photoluminescent analysis of the resulting composite was performed (Fig. 11).

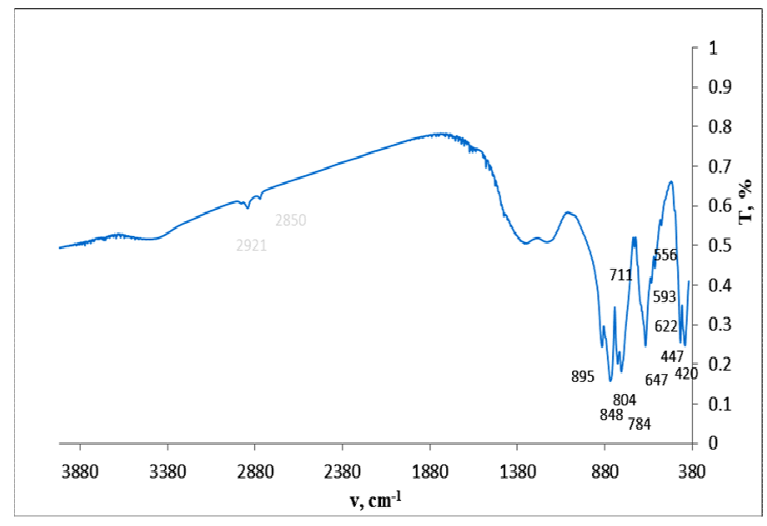

Figure 8: Infrared spectra of sample 5

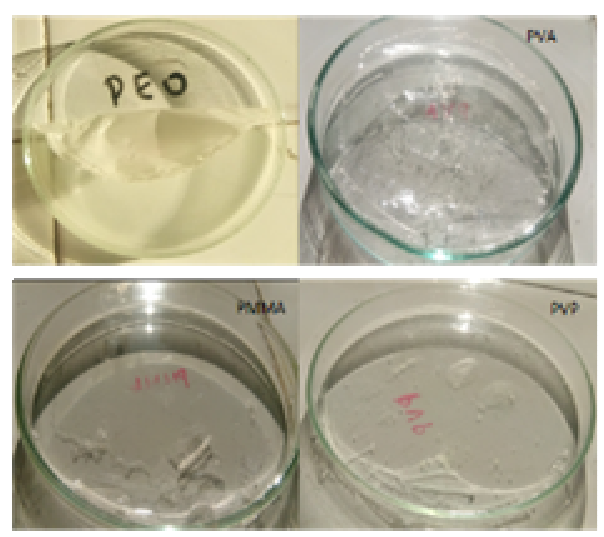

Figure 9: Polymer thin films after drying

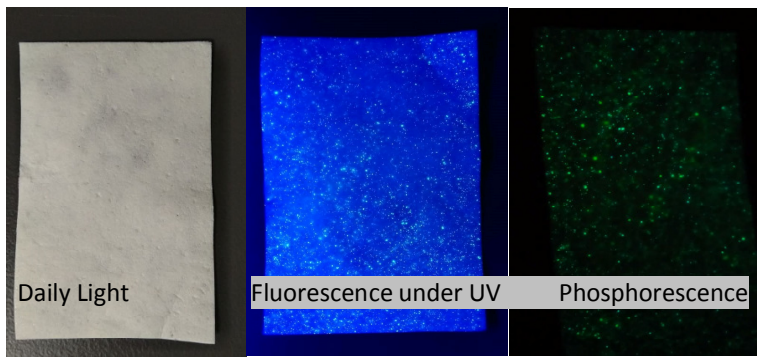

Figure 10: PEO-cellulose-luminophore composites on daylight and UV light 

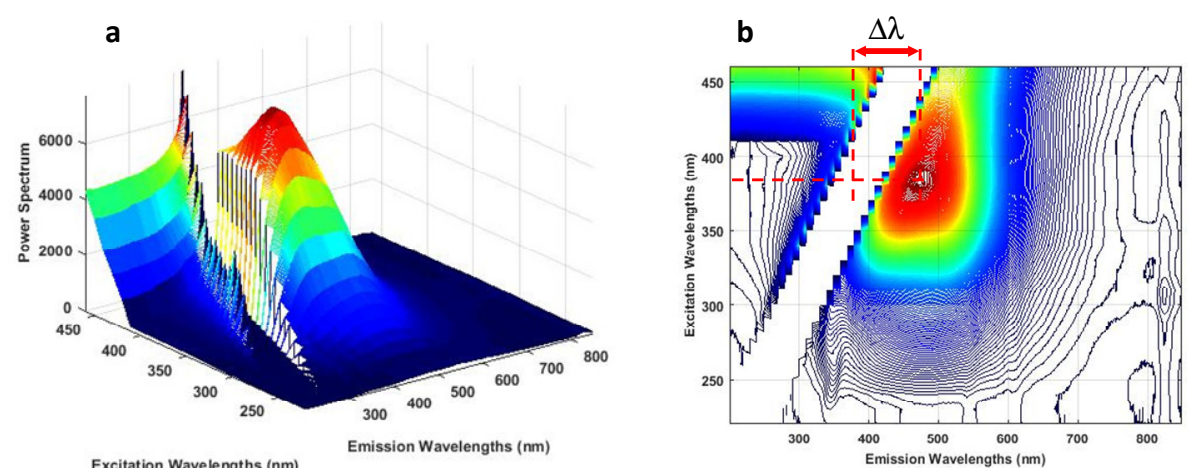

Figure 11: Fluorescent spectra of the composite material

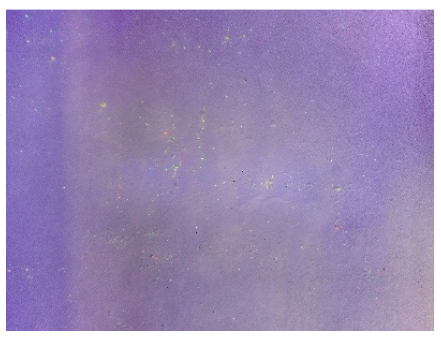

Figure 12: Polymeric slurry applied on paper under UV light

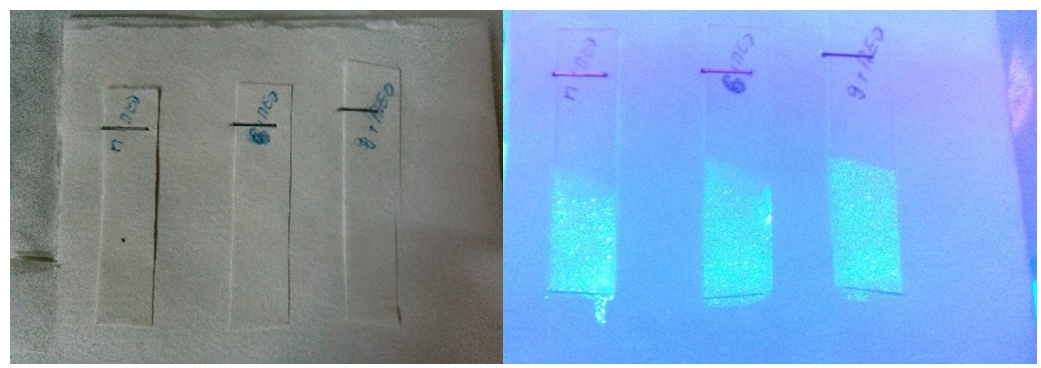

Figure 13: Submerged paper in polymer suspension in a) daylight, and b) under UV light

The intensity of emission in the visible area is increased rectilinearly by increasing the excitation length, the most effective being a diode with $\lambda=$ $380 \mathrm{~nm}$. The maximum of the emission intensity is about $473 \mathrm{~nm}$. The spectral offset is thus $\Delta \lambda=$ $473 \mathrm{~nm}-380 \mathrm{~nm}=93 \mathrm{~nm}$, which is the lowest measured so far. We noticed that the spectral shifts for the different samples vary largely between $93 \mathrm{~nm}$ to $308 \mathrm{~nm}$. Also, the fluorescence was weaker compared to the previous samples. The signals to the left of the white path are the result of the saturation of the excitation light.

For comparison, two other methods have been investigated: in the first, polymer slurries containing luminophore have been applied on paper; and in the second, the paper has been submerged in the slurry. The results obtained indicated that, when the polymeric slurry was applied to paper - as can be seen on the photo (Fig. 12) - there is good particle size distribution on the paper surface, but there is a likelihood of rusting in time if the particles have a larger size. Meanwhile, when paper was submerged in polymer suspension, very good particle distribution was achieved (Fig. 13). The results obtained are good, but there is a possibility of separating the top layer because of factors, such as the natural ageing process of the polymers, probability of wetting, friction and others.

\section{CONCLUSION}

The stoichiometric strontium aluminates obtained by the high-temperature solid phase procedure were characterized by XRD, IR and 


\section{IRENA KOSTOVA et al.}

photoluminescence methods. X-ray diffraction patterns indicated the presence of different phases in some of the samples, as well as the formation of a single crystal phase of $\mathrm{SrAl}_{2} \mathrm{O}_{4}: \mathrm{Eu}_{1.0} \mathrm{Dy}_{2.0}$. The formation of a single stoichiometric composition corresponded to high-fluorescence intensity, as well as to stronger and prolonged afterglow (phosphorescent), compared to the samples in which the formation of several crystalline phases was observed. Despite the difference, the samples obtained by hightemperature synthesis were highly fluorescent, noticeable in daylight. Experimental data show the best compatibility with polyethylene oxide and the possibility to prepare a polymer-celluloseluminophore type composite with desirable qualities and potential for different applications.

ACKNOWLEDGEMENT: Acknowledgements are due to the National Program of the Ministry of Education and Science "Young Scientist and Postdoctoral Students", Bulgaria.

\section{REFERENCES}

1 C. Zhang and J. Lin, Chem. Soc. Rev., 41, 7938 (2012), https://doi.org/10.1039/C2CS35215J

2 C. Feldmann, T. Justel, C. R. Ronda and P. J. Schmidt, Adv. Funct. Mater., 13, 511 (2003), https://doi.org/10.1002/adfm.200301005

3 G. Blasse and B. C. Grabmaier, "Luminescent Materials", Verlag, Berlin, 1994, pp. 112-126, https://doi.org/10.1007/978-3-642-79017-1

4 Y. Liu, D. Tu, H. Zhu and X. Y. Chen, Adv. Mater., 22, $3266 \quad$ (2010), https://doi.org/10.1002/adma.201000128

5 J. Andres, R. D. Hersch, J. E. Moser and A. S. Chovin, Adv. Funct. Mater., 24, 5029 (2014), https://doi.org/10.1002/adfm.201400298
6 R. L. Van Renesse, "Optical Document Security", $3^{\text {rd }}$ ed., Optoelectronics Library S., Boston Artech House, 2004, pp. 300-321

7 C. Hains, S. G. Wang and K. Knox, "Digital Colour Imaging Handbook", CRC Press, Boca Raton, 2003, pp. 385-490, https://doi.org/10.1201/9781420041484

C. Hagiopol and J. W. Johnston, "Chemistry of Modern Papermaking”, CRC Press, Boca Raton, 2011

9 C. Miao and W. Y. Hamad, Cellulose, 20, 2221 (2013), https://doi.org/10.1007/s10570-013-0007-3

10 A. Dufresne, Phil. Trans. R. Soc. A, 376, 20170040 (2017), https://doi.org/10.1098/rsta.2017.0040

11 R. E. Rojas-Hernandez, M. A. Rodriguez and J. F. Fernandez, RSC Adv., 5, $3104 \quad$ (2015), https://doi.org/10.1039/C4RA10460A

12 R. Ianoş, R. Istratie and C. Păcurariu, Phys. Chem. Chem. Phys., 18, $1150 \quad$ (2016), https://doi.org10.1039/c5cp06240c

13 S. H. Tatumi, A. F. Soares and D. R. G. Tudela, Radiat. Phys. Chem., 157, $15 \quad$ (2019), https://doi.org/10.1016/j.radphyschem.2018.12.013

14 Y. Liu and Ch. Xu, J. Phys. Chem. B, 107, 3991 (2003), https://doi.org/10.1021/jp022062c

15 Y. Zhang, L. Li, X. Zhang, D. Wang and S. Zhang, J. Rare Earths, 26, $656 \quad$ (2008), https://doi.org/10.1016/S1002-0721(08)60156-8

16 T. Matsuzawa, Y. Aoki, N. Takeuchi and Y. Murayama, J. Electrochem. Soc., 143, 2670 (1996), https://doi.org/10.1149/1.1837067

17 H. Xiang, Z. Xu, V. A. L. Roy and C.-M. Che, Rev. Sci. Instrum., $\quad \mathbf{7 8 ,} 034104 \quad$ (2007), https://doi.org/10.1063/1.2712932

18 D. Dutczak, T. Justel, C. Rondac and A. Meijerink, Phys. Chem. Chem. Phys., 17, 15236 (2015), https://doi.org/10.1039/C5CP01095K

19 H. G Ahalya, B. H. Doreswamy and B. M. Nagabhushana, J. Sci. Eng. Technol., 1, 499 (2014), http://jset.sasapublications.com/wpcontent/uploads/2017/09/6702370.pdf 